\title{
First Australian pregnancy after ovarian tissue cryopreservation and subsequent autotransplantation
}

Lynn Burmeister MB BS, FRANZCOG, CREI Clinical Director

Gabor T Kovacs MD, FRANZCOG, CREI International Medical Director

Tiki Osianlis BSc(Hons), PhD, Scientific Director Embryology

Monash IVF Melbourne, VIC

gkovacs@ monashivf.com

doi: 10.5694/mial2.11768

Online first 11/02/13

\begin{abstract}
We describe the first pregnancy in Australia after fertility preservation by freezing of ovarian tissue for 7 years and subsequent autotransplantation in a woman treated for breast cancer, who was menopausal after chemotherapy. After transplantation and in-vitro fertilisation, she has a viable ongoing pregnancy.
\end{abstract}

\section{Clinical record}

A 37-year-old woman presented in September 2005 with Grade 2 to 3 invasive ductal breast carcinoma that was oestrogen and progesterone receptor positive. Options for fertility preservation were discussed, and she decided to proceed with ovarian tissue freezing before commencing high-dose gonadotoxic chemotherapy. Laparoscopic partial left oophorectomy was performed. A wedge of about $1 \times 2 \mathrm{~cm}$ of ovarian tissue was cut with scissors without using coagulation.

The ovarian wedge was placed into chilled phosphate buffered saline (PBS) and, under sterile conditions, the ovarian cortex was dissected away from the medulla. The cortex, which was about $1 \mathrm{~mm}$ thick, was cut into $5 \times 5 \mathrm{~mm}$ squares and transferred into $1.5 \mathrm{M}$ dimethyl sulfoxide (DMSO) and 0.1 M sucrose in Dulbecco's PBS $14 \mathrm{~mL}$ tubes and held at $0^{\circ} \mathrm{C}$ for 30 minutes. The tubes were agitated every 5-10 minutes. After 30 minutes, two to three pieces of ovarian tissue were placed into each of six chilled cryovials containing $1.5 \mathrm{M}$ DMSO and $0.1 \mathrm{M}$ sucrose in PBS, and the cryovials were placed into the CryoLogic slow freeze machine at $0^{\circ} \mathrm{C}$ for 30 minutes. The temperature of the cryovials was decreased to $-6^{\circ} \mathrm{C}$ at a rate of $-2^{\circ} \mathrm{C} / \mathrm{min}$. After 5 minutes at $-6^{\circ} \mathrm{C}$, the cryovials were seeded, thereby inducing ice crystal formation. The freezing program then ran at $-0.3^{\circ} \mathrm{C} / \mathrm{min}$ to $-40^{\circ} \mathrm{C}$, and the cryovials were plunged into liquid nitrogen and stored.

The woman presented again in 2011, at the age of 43 years, desiring to achieve a pregnancy. Her serum folliclestimulating hormone (FSH) level was persistently above $30 \mathrm{IU} / \mathrm{L}$ (premenopausal reference interval [RI], < $25 \mathrm{IU} / \mathrm{L}$ ), her oestradiol level was below $44 \mathrm{pmol} / \mathrm{L}$, implying no ovarian activity, there were no signs of ovulation, and she had an anti-Müllerian hormone level of $<1 \mathrm{ng} / \mathrm{mL}$ (normal ovarian reserve, $>14 \mathrm{ng} / \mathrm{mL}$ ). After consultation with oncologists, she decided to proceed with autologous ovarian tissue reimplantation, which was performed in April 2012.

The operation was performed using minilaparotomy. The cryovials containing the ovarian tissue were immersed in a $37^{\circ} \mathrm{C}$ waterbath until the cryoprotectant solution had thawed and liquefied. The pieces of ovarian tissue were removed and placed into $0.75 \mathrm{M}$ DMSO and $0.25 \mathrm{M}$ sucrose for 10 minutes, then $0.25 \mathrm{M}$ sucrose for a further 10 minutes, and held in PBS until ready for transplant. Each ovary was exposed and appeared very atrophic. The capsule of each ovary was incised, and four pieces of ovarian tissue were inserted subcapsularly into the left ovary, and six pieces into the right ovary. The incisions were closed with 3-0 vicryl. The woman stayed in hospital for 24 hours, and made a speedy uneventful recovery.

After the surgery, the woman's FSH level remained above $30 \mathrm{IU} / \mathrm{L}$, but some ovarian function was noted, with elevation of the oestradiol level to $107 \mathrm{pmol} / \mathrm{L}$ in July 2012. However, ultrasound examination at that time showed no follicular activity. In August 2012, a peak oestradiol level of $1166 \mathrm{pmol} / \mathrm{L}$, with an FSH level of $10.2 \mathrm{IU} / \mathrm{L}$, was recorded, suggesting ovarian activity, but ongoing monitoring of blood levels did not show an elevation of progesterone. In September 2012, natural menstruation occurred, and she was monitored daily with blood tests and follicle tracking - a $16 \mathrm{~mm}$ follicle was noted on ultrasound scan. Natural ovulation occurred on Day 19 of the cycle, and the peak progesterone level after ovulation was recorded at $8.5 \mathrm{nmol} / \mathrm{L}$ (luteal phase RI, $>5 \mathrm{nmol} / \mathrm{L}$ ).

A decision was then made to proceed with an in-vitro fertilisation (IVF) cycle and to use an aromatase inhibitor, letrozole, at $2.5 \mathrm{mg}$ per day from Day 2 to Day 6 of a natural menstrual cycle for ovarian stimulation, with an antagonist (ganirelix acetate) starting on Day 5. The usual mode of controlled ovarian hyperstimulation using $\mathrm{FSH}$ was avoided, because of the theoretical risk of elevated oestrogen levels. On Day 10 of the cycle, one $16 \mathrm{~mm}$ follicle and one $9 \mathrm{~mm}$ follicle were noted. The peak oestradiol level recorded on Day 10 was 267 pmol/L. Recombinant choriogonadotropin alfa was used to trigger ovulation 36 hours before transvaginal oocyte retrieval. Two oocytes were collected in October 2012, one of which was mature. Fertilisation was achieved through intracytoplasmic sperm injection, and the embryo was transferred on Day 3 after oocyte retrieval, at the 10-cell stage. Progesterone vaginal gel $8 \%$ (90 mg daily) was commenced 1 day after oocyte retrieval and human chorionic gonadotropin (hCG) 
Vaginal ultrasound performed at 6 weeks and 3 days, confirming a viable pregnancy

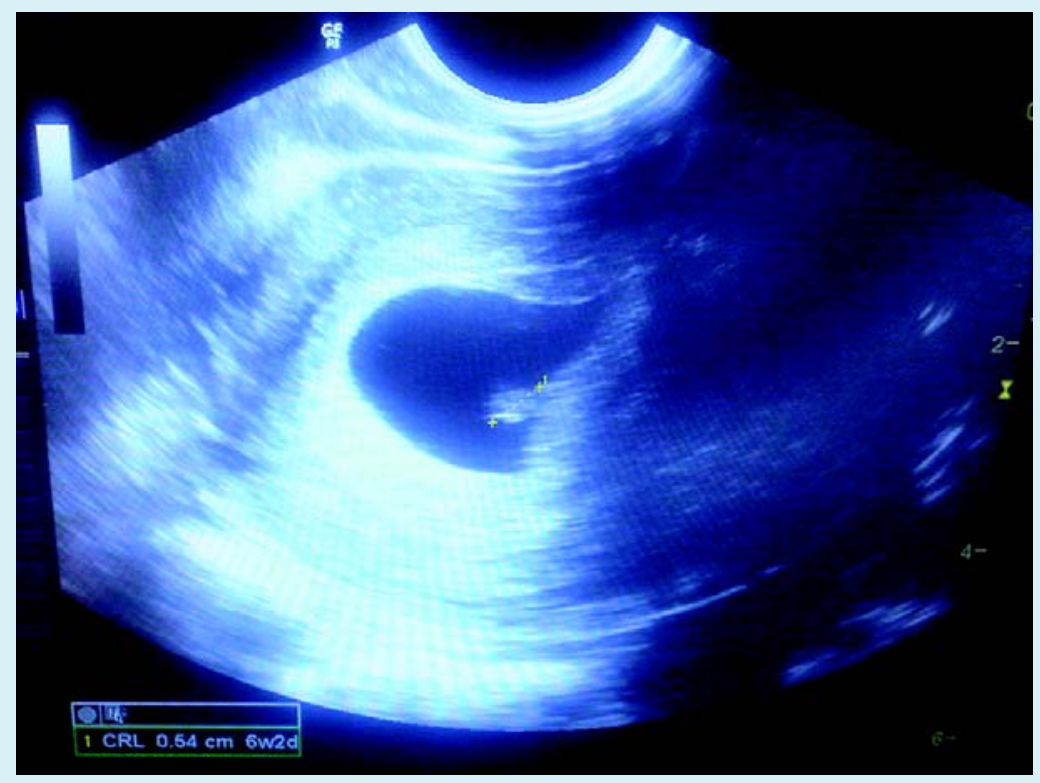

(1500 IU per day) was administered subcutaneously on Days 3, 6 and 9 after oocyte retrieval for luteal support.

Fifteen days after oocyte retrieval, the woman had a $\beta$ hCG level of $259 \mathrm{IU} / \mathrm{L}$ and a progesterone level of $71.6 \mathrm{nmol} / \mathrm{L}$. She continued vaginal progesterone treatment. At 5 weeks, she had a $\beta$-hCG level of $5140 \mathrm{IU} / \mathrm{L}$ and a progesterone level of $76.4 \mathrm{nmol} / \mathrm{L}$. A vaginal ultrasound was performed at 6 weeks and 3 days, in November 2012, and a viable intrauterine pregnancy was confirmed, with a fetal heart rate of 120 beats/min (Box).

\section{Discussion}

The pregnancy reported here is the first in Australia to occur after ovarian cryopreservation and autotransplantation. The first reported birth of a naturally conceived child after orthotopic transplantation of thawed frozen ovarian tissue was described in 2004. ${ }^{1}$ A pregnancy was subsequently reported where routine IVF with controlled ovarian hyperstimulation and transvaginal oocyte collection was carried out after orthotopic transplantation of ovarian tissue. ${ }^{2}$

After a review of fertility preservation options, ${ }^{3}$ we have now undertaken two attempts at ovarian autotransplantation using thawed cryopreserved ovarian cortex; the pregnancy described here represents the second of these. Our first attempt involved a woman who had pieces of ovarian cortex frozen at the age of 39 years in 2001 and subsequently underwent a natural menopause (serum FSH levels > 25 IU/L on two occasions). The ovarian tissue was reimplanted in 2009 and ovarian function returned, with FSH levels decreasing to premenopausal levels (7 IU/L and $12 \mathrm{IU} / \mathrm{L})$ and oestrogen levels of up to $663 \mathrm{pmol} / \mathrm{L}$, and with menstruation temporarily resuming. However, one attempt at controlled ovarian hyperstimulation was unsuccessful, and the woman declined further attempts.

A recent review reported that 17 babies had been conceived after ovarian cryopreservation and autotransplantation in 12 women in eight centres by the end of 2011. ${ }^{4}$ There has since been a report of a successful pregnancy in Germany. ${ }^{5}$ We therefore presume that the pregnancy reported here is one of the first 20 of its kind in the world, and only the second in a woman successfully treated for breast cancer.

It is not possible to express the success rate for autotransplantation of cryopreserved ovarian tissue, as we do not know how many attempts have been made to reimplant thawed frozen ovarian tissue in women (the denominator). ${ }^{6}$ The fact that both our attempts to date showed some degree of success, with the second achieving a pregnancy, may suggest this could become a preferred method of fertility preservation. It has the advantage that the ovarian tissue can be collected within 24 hours, no hormones need to be administered at the time of the cancer diagnosis, and the procedure takes less than half an hour and can be performed by any gynaecologist. The freezing technique is relatively straightforward, and storage facilities are available in every IVF unit. The process at the time of cancer diagnosis is also relatively inexpensive, as it only requires an operative laparoscopy and a few hours of a laboratory scientist's time.

We performed the transplantation through a minilaparotomy, rather than laparoscopically, on the advice of our Israeli colleagues who had achieved two pregnancies by this technique. ${ }^{2}$ This enabled a much quicker procedure than laparoscopy and minimised tissue damage.

One reservation about ovarian tissue autotransplantation in women with a malignancy is the theoretical risk of retransplanting malignant cells. However, although this is a potential risk in the presence of a haematogenous malignancy, the concern with breast cancer is minimal as the tiny pieces of ovarian tissue would be most unlikely to contain metastatic cancer cells.

While technology needs to be developed and made available to increase the choices for fertility preservation for medical reasons, ${ }^{7}$ there is also a possible application of this technique in delaying or avoiding the menopause.

Competing interests: No relevant disclosures.

Received 4 Dec 2012, accepted 17 Jan 2013.

1 Donnez J, Dolmans MM, Demylle D, et al. Livebirth after orthotopic transplantation of cryopreserved ovarian tissue. Lancet 2004; 364: 1405-1410.

2 Mierow D, Levron J, Eldar-Geva T, et al. Pregnancy after transplantation of cryopreserved ovarian tissue in a patient with ovarian failure after chemotherapy [letter]. N Engl J Med 2005; 353: 318-321.

3 Kovacs GT, Rutherford AJ, Howlett D. Fertility preservation for women. O\&G 2006; 8 (1): 12-14

4 Silber SJ. Ovary cryopreservation and transplantation for fertility preservation. Mol Hum Reprod 2012; 18: 59-67.

5 Isachenko V, Isachenko E, Keck G, et al. First live birth in Germany after retransplantation of cryopreserved ovarian tissue: original device for initiation of ice formation. Clin Lab 2012; 58: 933-938.

6 Wallace WH, Kelsey TW, Anderson RA. Ovarian cryopreservation: experimental or established and a cure for the menopause? Reprod Biomed Online 2012; 25: 93-95.

7 Kovacs GT, Stern K. Reproductive aspects of cancer treatment: an update. Med J Aust 1999; 170: 495-497. 